\title{
ENCUENTROS ENTRE LAS JUSTICIAS INDÍGENA Y \\ RESTAURATIVA EN COLOMBIA
}

\section{Tereza Dlestikova}





\title{
ENCUENTROS ENTRE LAS JUSTICIAS INDÍGENA Y RESTAURATIVA EN COLOMBIA
}

\author{
Tereza Dlestikova \\ Universidad Carolina de Praga
}

\section{Resumen}

El texto dedica su parte introductoria al concepto del pluralismo jurídico, al derecho propio de los pueblos indígenas en Colombia y a su cosmovisión, con el enfoque al pueblo nasa ubicado en el departamento del Cauca. A continuación, se destacan los aspectos cruciales de las prácticas ancestrales relativas a la resolución de conflictos, las cuales son el reconocimiento de la responsabilidad por el transgresor, su sentimiento de vergüenza, el perdón de la víctima y la restitución del estado inicial, con el fin de reinsertar a la persona desviada a la comunidad, a recuperar de la paz social y, en general, a prevenir conflictos.

Tras señalar los rasgos principales de las formas tradicionales indígenas de dar respuesta a situaciones conflictivas, se concluye que estas tienen puntos de encuentro con la justicia restaurativa, por lo que la indígena podría ser un buen ejemplo para el derecho penal occidental y enriquecerlo con las ideas restaurativas y pacificadoras, desde una perspectiva del derecho contemporáneo.

Palabras clave: pluralismo jurídico, comunidades indígenas, Colombia, jurisdicción especial indígena, justicia restaurativa, resolución de conflictos.

El autor: doctora en Derecho. Docente Universidad Carolina de Praga. Correo electrónico: terezadlestikova@ gmail.com

Recibido: 30 de enero de 2019; evaluado: 21 de agosto 21 de 2019; aceptado: 2 de septiembre de 2019. 


\title{
INDIGENOUS AND RESTORATIVE JUSTICE MEETING POINTS
}

\author{
Tereza Dlestikova \\ Universidad Carolina de Praga
}

\begin{abstract}
The introductory part of the article focuses on the concept of legal pluralism, on the legal system of indigenous communities in Colombia and their own worldview, with an emphasis on the Nasa people located in the Cauca Department. Then, it underlines the key aspects of ancestral practices related to dispute resolution, which are the offender's recognition of responsibility, his feeling of shame, the victim's forgiveness, and the restitution of the original state, in order to reintegrate the transgressor to the community, to recover the social peace and, in general, to prevent conflicts.

After pointing out the main features of traditional indigenous dispute resolution forms, the article concludes that there are similarities between indigenous and restorative justice. Thus, indigenous law could be an inspiration for the modern criminal law regarding the restorative and conciliatory issues, from the contemporary law point of view.
\end{abstract}

Keywords: legal pluralism, indigenous communities, Colombia, indigenous jurisdiction, restorative justice, dispute resolution.

About the author: Doctor in Law. Professor at Universidad Carolina de Praga. Email: terezadlestikova@ gmail.com

Received: January 30, 2019; evaluated: August 21, 2019; accepted: September 2, 2019. 


\title{
PONTOS DE ENCONTRO ENTRE A JUSTIÇA INDÍGENA E A JUSTIÇA RESTAURATIVA
}

\author{
Tereza Dlestikova \\ Universidad Carolina de Praga
}

\section{Resumo}

Este artigo se enfoca, em sua parte introdutória, no conceito de pluralismo legal, no sistema legal de comunidades indígenas na Colômbia e em sua própria visão de mundo, com ênfase na comunidade Nasa, situada na região do Cauca. Portanto, destaca os principais aspectos das práticas ancestrais relacionadas à resolução de disputas, que são o reconhecimento da responsabilidade do infrator, seu sentimento de vergonha, o perdão da vítima e a restituição do estado original a fim de reintegrar o transgressor à comunidade, recuperar a paz social e, em geral, evitar conflitos.

Depois de apontar as principais características das formas tradicionais de resolução de disputas dos nativos, o artigo conclui que existem similaridades entre a justiça indígena e a justiça restaurativa. Por esse motivo, as práticas legais ancestrais poderiam servir de inspiração para o Direito Penal moderno com respeito às questões restaurativas e conciliatórias, do ponto de vista do Direito contemporâneo.

Palavras-chave: pluralismo legal, comunidades indígenas, Colômbia, jurisdição indígena, justiça restaurativa, resolução de disputa.

O autor: doutora em Direito. Professora da Universidad Carolina. E-mail: terezadlestikova@gmail.com

Recebido: 30 de janeiro de 2019; avaliado: 21 de agosto de 2019; aceito: 2 de setembro de 2019. 


\section{Introducción}

El presente texto comparativo tiene como pretensión buscar y resaltar los puntos de encuentro entre la justicia restaurativa y las prácticas ancestrales relativas a la resolución de conflictos de tipo penal.

A primera vista, puede parecer que se pretende comparar lo incomparable, ya que la justicia indígena y la restaurativa son paradigmas procedentes de distintas percepciones del mundo — la indígena y la occidental_- pero se demuestra que se basan en una filosofía parecida. Tras la búsqueda de sus puntos de encuentro, se vinculan estos dos mundos que parecen tan distintos, pero no lo son, con lo que la justicia indígena podría resultar inspiradora para la occidental.

Antes de exponer la comparación, resulta imprescindible abordar tanto el concepto del pluralismo jurídico y la jurisdicción especial indígena como el derecho propio de los pueblos indígenas en Colombia, su cosmovisión y la justicia restaurativa. Por lo tanto, el marco teórico comprende el pluralismo jurídico, la justicia restaurativa, la teoría de despenalización —-representada por la criminología crítica y el minimalismo penal basado en el principio de la reducción de la represión—, la teoría de Claus Roxin sobre la reparación como la consecuencia jurídica de la comisión del delito, ya que todas estas vertientes se han centrado en la búsqueda de alternativas de solución de los conflictos penales. En cuanto a la metodología, se recurrió al análisis teórico de la literatura y a la investigación empírica, consistente en las entrevistas con los comuneros nasa en el departamento del Cauca.

\section{Pluralismo jurídico y jurisdicción especial indígena en Colombia}

Colombia es una sociedad con valores específicos y con diferentes contextos, cosmovisiones y sistemas económicos, sociales y jurídicos. ${ }^{1}$

Griffiths entiende por la pluralidad jurídica "la situación dentro del cualquier campo social en la cual ocurren comportamientos que obedecen a más de un ordenamiento jurídico". 2

Marcela Gutiérrez, "Pluralismo jurídico y cultural en Colombia", Derecho del Estado, núm. 26 (enero-junio 2011): 87, http://www.scielo.org.co/pdf/rdes/n26/n26a04.pdf (acceso octubre 3, 2018)

2 John Griffiths, "¿Qué es pluralismo jurídico?" en Pluralismo jurídico, ed. Sally Engle Merry, John Griffiths y Brian Tamanaha (Bogotá: Universidad de los Andes, 2007), 146. 
El concepto del pluralismo jurídico comprende la complejidad de los derechos que se encuentran tanto en las sociedades contemporáneas como en los derechos y las prácticas jurídicas de las culturas tradicionales o la relación entre los derechos de las sociedades occidentales y las tradicionales. ${ }^{3}$

La especificidad del pluralismo legal no trata de negar el derecho estatal, sino de reconocer que este es una de las muchas formas jurídicas que pueden existir en la sociedad. ${ }^{4}$

Debido a que en un espacio determinado se hallan distintas culturas con sus respectivas prácticas jurídicas o reguladoras, el pluralismo jurídico se relaciona, en parte, con el pluralismo cultural, ${ }^{5}$ por lo que implica el reconocimiento de la coexistencia de varios órdenes culturales y varios sistemas normativos, uno de los cuales es el sistema jurídico indígena, que ofrece, entre otras cosas, una respuesta a la desviación social similar a la que ofrece el proceso penal occidental.

El pluralismo legal está relacionado con el principio de la diversidad cultural, según el cual las culturas poseen sus cosmovisiones particulares, que incluyen el campo jurídico. ${ }^{6}$ El principio de la diversidad étnica y cultural de la Nación es el principio constitucional y el derecho de los pueblos indígenas para administrar justicia según sus propios usos y costumbres, denominada jurisdicción especial indígena, está reconocido y protegido por la Constitución colombiana (art. 246). El reconocimiento constitucional de dicha jurisdicción se fundamenta en el concepto teórico del pluralismo jurídico ${ }^{7}$ y está ligado a la aceptación de los procedimientos internos, a sus propios usos y costumbres y al derecho de los pueblos indígenas a la autodisposición, por la que se entiende la organización y la gobernación del grupo étnico según su propia visión del mundo y sus tradiciones.

En las Sentencias C-139 de 1996 y Sentencia SU-510 de 1998, la Corte Constitucional colombiana ha definido cuatro elementos que definen la jurisdicción especial indígena: i) autoridades indígenas, es decir, autoridades judiciales propias de los

3 Jairo Vladimir Llano, "Relaciones entre la sociología y la antropología jurídica en Latinoamérica", Iusta 2, núm. 33 (2010): 106, https://revistas.usantotomas.edu.co/index.php/iusta/article/view/3098 (acceso octubre 3, 2018).

4 Antonio Carlos Wolkmer, Pluralismo jurídico: nuevo marco emancipatorio en América Latina (Buenos Aires: Cenejus, 2003), 7.

5 Jairo Vladimir Llano, Teoría del Estado y del derecho: pluralismo jurídico (Bogotá: Ibáñez, 2017), 24.

6 Llano, Teoría del Estado, 14.

7 Llano, "Relaciones", 111. 
pueblos indígenas, quienes administran justicia dentro de sus comunidades de acuerdo con su estructura social y cosmovisión; ii) la competencia de los pueblos indígenas para fijar normas y procedimientos propios, definidos en su derecho propio; iii) los límites de la jurisdicción representadas por la Constitución y la ley, y iv) la competencia del Legislador para señalar la forma de coordinación entre la jurisdicción especial indígena y las autoridades nacionales. ${ }^{8}$ Dichos elementos crean el fuero indígena, el cual tiene un alcance territorial y personal; esto quiere decir que la jurisdicción indígena está limitada por el espacio geográfico y la integración de la persona a la comunidad. En otras palabras, el principio de la territorialidad y de la personalidad consiste en que las autoridades de cada pueblo indígena pueden conocer los hechos ocurridos dentro del resguardo ocupado por la comunidad, dada la pertenencia étnica de los individuos involucrados en el conflicto y los intereses en juego. ${ }^{9}$

El pluralismo jurídico pretende ofrecer una comprensión de la realidad, en la que culturas diferentes compartan un mismo espacio. Tiene que ver con la solidaridad, con una ética que gestione y procure una sociedad del respeto, ya que se debilita cualquier pretensión de objetividad e imposición de unos valores éticos, políticos y sociales que presione a un individuo o grupo para que crea o acepte, sin más, una cosa, una condición o un hecho. ${ }^{10}$ Ese es el fundamento para legitimar la jurisdicción indígena, que es la afirmación tanto de la diferencia cultural para ejercer justicia propia, distinta a la del Estado como de su propósito de autonomía política para ejercerla de forma interna sin la injerencia del Estado. ${ }^{11}$

\section{Derecho propio indígena en Colombia}

Para Colombia, un Estado pluriétnico y multicultural, es característica la diversidad cultural y la coexistencia de diversos grupos sociales. Con la sociedad mayoritaria

8 Rosembert Ariza Santamaría, "Estado del relacionamiento en Colombia" en Estado de la relación entre justicia indígena y justicia estatal en los países andinos. Estudio de casos en Colombia, Perú, Ecuador y Bolivia, ed. Comisión Andina de Juristas (Lima: Comisión Andina de Juristas, 2009), 19.

$9 \quad$ Esther Sánchez Botero, "Reflexiones antropológicas en torno a la justicia y la jurisdicción especial indígena en una Nación multicultural y multiétnica” en Las sociedades interculturales: un desafí para el siglo XXI, coord. Fernando García (Quito: Flacso, 2000)

10 Carlos Alfonso Cárdenas Hernández y Pedro Alfonso Sánchez Cubides, "El pluralismo jurídico en la jurisdicción indígena y el buen vivir en Colombia", Criterio jurídico garantista 9, núm. 15 (julio-diciembre, 2016): 20, http://revistas.fuac.edu.co/index.php/criteriojuridicogarantista/article/view/646/599 (acceso octubre 3 2018).

11 Herinaldy Gómez Valencia, Justicias indígenas de Colombia: reflexiones para un debate cultural, jurídico y político: pueblos Kogui, Arhuaco, Wiwa, Kankuamo, Nasa, Misak, Yanacona y Camëntŝá (Bogotá: Consejo Superior de la Judicatura, 2015), 114. 
conviven los pueblos indígenas, cuyas condiciones sociales, culturales y económicas las distinguen de otros sectores de la colectividad nacional, ya que están regidos total o parcialmente por sus propias costumbres, tradiciones y legislación especial. ${ }^{12}$

El derecho forma parte de cada grupo cultural y es un fenómeno dinámico. ${ }^{13}$ Por derecho propio o interno, Ley de Origen, derecho mayor o leyes de la Madre Tierra se entienden las tradiciones jurídicas ancestrales, preexistentes a los ordenamientos jurídicos estatales, basados en los usos y las costumbres, pero no limitados a ellos, que los pueblos indígenas usan para regular sus asuntos internos. Se refieren a todos los aspectos de la vida y la organización social y están estrechamente ligados a las prácticas culturales cotidianas de los grupos étnicos. ${ }^{14}$

El derecho mayor procede de la tradición oral, de los usos y las costumbres y se mantiene en la memoria colectiva. Según su lógica y experiencia, no hay necesidad de escribir lo que ya está inscrito en la cultura y la memoria. ${ }^{15}$ La transmisión oral de los conocimientos, la cultura y las tradiciones sustituye los procedimientos escritos de información social propios de los sistemas occidentales. Esta premisa también fundamenta la materia penal, ya que, mediante la costumbre, los comuneros saben cuál conducta se considera divergente —en la lengua occidental, ilícita-y cuáles son sus consecuencias. Así se alcanzan los fundamentos de la legalidad, el principio rector del proceso penal ordinario: la sabiduría de la costumbre garantiza la seguridad jurídica e igualdad de los comuneros. ${ }^{16}$

En materia penal, el sistema jurídico indígena no se orienta a determinar la conducta divergente. "La prohibición en los pueblos indígenas está relacionada directamente con una acción y con la idea de efecto; no es posible transgredir una norma sin que acarree consecuencias negativas; la sanción es entonces inmanente y ligada a la

\footnotetext{
12 Organización Internacional del Trabajo [OIT], Convenio núm. 169 de la OIT sobre pueblos indígenas y tribales en países independientes (Ginebra, 7 de junio de 1989.), art. 1 a).

13 Leopold Jaroslav Pospíšil e Ivan Dubovický, Etnologie prâva: teze ke studiu práva z mezikulturní perspektivy (Praga: Setout, 1997), 36.

14 Javier Rodríguez, Acceso a la justicia de los pueblos indígenas: guía para la atención especializada por parte de las oficinas del Ombudsman (San José: Instituto Interamericano de Derechos Humanos, 2006), 23.

15 Gómez Valencia, Justicias indígenas, 189.

16 Emiliano Borja Jiménez, "Derecho indígena, sistema penal y derechos humanos", Nuevo foro penal 5, núm. 73 (2009): 14, https://dialnet.unirioja.es/descarga/articulo/3822976.pdf (acceso octubre 3, 2018).
} 
transgresión". ${ }^{17}$ Por ejemplo, en el pueblo paez, las autoridades disponen diferentes formas de sanción según el delito concreto y sus circunstancias. ${ }^{18}$

La regulación jurídica indígena no se percibe como exterioridad, sino como interioridad del sujeto y del colectivo. ${ }^{19}$ Está estrechamente vinculada a los valores y las creencias y refleja la cosmovisión indígena; por eso, no se puede evaluar desde la óptica occidental, pues hace falta conocer la cosmovisión indígena y entenderla bien.

\section{Cosmovisión de los pueblos indígenas en Colombia}

Por cosmovisión indígena se entiende su propia manera de pensar, actuar, vivir e interpretar la realidad y la vida, así como administrarla de acuerdo con las propias costumbres. La cosmovisión indígena es el elemento fundamental de su identidad, es la razón de ser, la conexión con la Madre Tierra y el mundo natural, sin el cual un indígena no concibe su existencia. ${ }^{20}$

Para la comunidad indígena es inmanente la convivencia colectiva, la cual no se encuentra mediada por los miembros individuales del grupo étnico, ya que el individuo no concibe una existencia separada de la comunidad, ${ }^{21}$ pues la convivencia consiste en la mutua dependencia entre todos. Los principios clave de la convivencia indígena son la reciprocidad y las relaciones de horizontalidad y de igualdad, porque la reciprocidad y la redistribución hacen la sociedad más igualitaria, así como la solidaridad que es el vínculo del individuo con la comunidad y la armonía y el equilibrio social, y todo eso abarca el principio de comunidad que también se proyecta a la justicia. La justicia se percibe como sentido de convivencia, estar contento, vivir bien con tranquilidad interior, compartir y sentirse parte de una comunidad. ${ }^{22}$ La comunidad es el centro de la vida, es la cotidianidad que se refleja

17 Esther Sánchez Botero, Justicia y pueblos indígenas de Colombia: la tutela como medio para la construcción de entendimiento intercultural (Bogotá: Universidad Nacional de Colombia, 1998), 157, 164.

18 Esther Sánchez Botero, "Principios básicos y formas de funcionamiento de la justicia que se imparte entre los paeces y los wayuu como forma cultural adecuada, legítima y viable para resolver conflictos y coaccionar a sus sociedades particulares" en Hacia sistemas jurídicos plurales, reflexiones y experiencias de coordinación entre el derecho estatal y el derecho indigena, ed. Rudolf Huber et al. (Bogotá: Anthropos, 2008), 135.

19 Gómez Valencia, Justicias indígenas, 366.

20 Jorge Enrique Benavides Ascuntar, "La jurisdicción indígena en el sistema penal acusatorio", Entramado 7 , núm. 2 (julio-diciembre 2011): 109, http://www.scielo.org.co/pdf/entra/v7n2/v7n2a07.pdf (acceso octubre 3, 2018).

21 Sánchez Botero, "Reflexiones antropológicas".

22 Herinaldy Gómez Valencia, "Autoridad y control social en pueblos indígenas andinos de Colombia", Ra Ximhai 2, núm. 3 (septiembre-diciembre 2006): 697, https://dialnet.unirioja.es/descarga/articulo/2213976. pdf (acceso octubre 3, 2018). 
en la dinámica de la vida de los indígenas y sus pueblos. ${ }^{23}$ Por eso se trata de la justicia consensual y colectiva que se basa en la idea de que el error que comete una persona daña a todos los miembros de la comunidad y debe solucionarse en comunidad.

La justicia tiene la naturaleza colectiva, por lo cual los derechos son reconocidos en su relación con la comunidad, no con los sujetos específicos. ${ }^{24}$ Se fundamenta en la tradición y la costumbre como una especie de conciencia mítica, como algo que está en el origen y sentido de las cosas, como una lógica de la vida; por lo tanto, las prácticas jurídicas poseen un origen ancestral y mítico, más que un sentido humano. ${ }^{25}$

Conforme a la cosmovisión paez, el sujeto de derecho es toda la comunidad y la comunidad es la unidad, el sujeto colectivo, el grupo, el nosotros. ${ }^{26}$ Para los nasa, la justicia es la búsqueda de la relación armoniosa entre la comunidad, el sujeto y la naturaleza. ${ }^{27}$ La relación del ser humano y la naturaleza es tan estrecha que es necesario equilibrar el flujo de la vida para una armonía profunda que debe cuidarse para que no se altere. ${ }^{28}$

En la justicia indígena también están presentes la simbología y la ritualidad, pues sin la ayuda del símbolo y del ritual, el derecho no sería más que una ilusión. ${ }^{29}$ Asimismo, la justicia está estrechamente vinculada con el sistema religioso, con la salud y la enfermedad de los individuos y con la armonía de la comunidad. ${ }^{30}$

En la cosmovisión indígena, quienes cometen faltas causan desequilibrio en la comunidad y violan su armonía; se consideran enfermos, poseídos por espíritus o

23 Elisa Cruz Rueda, "Principios generales del derecho indígena" en Hacia sistemas jurídicos plurales, reflexiones y experiencias de coordinación entre el derecho estatal y el derecho indigena, ed. Rudolf Huber et al. (Bogotá: Anthropos, 2008), 35.

24 Gómez Valencia, Justicias indígenas, 200, 202.

25 Cruz Rueda, "Principios generales", 39.

26 Sánchez Botero, "Principios básicos", 127.

27 Gómez Valencia, "Autoridad", 689.

28 Sánchez Botero, Justicia, 162.

29 Akuavi Adonon Viveros, "La conciliación: ¿Un medio o un fin en la solución de conflictos?" en Hacia sistemas jurídicos plurales, reflexiones y experiencias de coordinación entre el derecho estatal y el derecho indígena, ed. Rudolf Huber et al. (Bogotá: Anthropos, 2008), 97.

30 Sánchez Botero, Justicia, 156. 
víctimas de maldiciones. ${ }^{31}$ Los miembros del pueblo paez interpretan la presencia del sujeto transgresor en sus comunidades como la manifestación de la ruptura del orden social. ${ }^{32}$ De forma parecida, según la cosmovisión nasa, las personas que cometen una desarmonización están enfermas física y espiritualmente y rompen la armonía, por lo cual hay que corregirlas y sacudir la enfermedad que las llevó a desarmonizarse o sacar el espíritu negativo y restablecer el equilibrio perdido y regresar a la paz. ${ }^{33}$ El daño causado se puede percibir también como un mal causado por un agente externo. ${ }^{34} \mathrm{El}$ incumplimiento de las reglas de convivencia se observa como la amenaza contra la cooperación social, cuya presencia confirma que el sujeto o el colectivo étnico están desviándose de la normatividad cultural. ${ }^{35}$

La concepción indígena del conflicto o de la desviación social es positiva, es decir, es una oportunidad para fortalecer la reciprocidad y la cohesión en la comunidad, ya que la reciprocidad y la generosidad son principios de alcance moral y ético y resultan esenciales para la convivencia. ${ }^{36} \mathrm{~A}$ pesar de que las partes están en conflicto, tienen un propósito común: restaurar las relaciones afectadas.

\section{Las prácticas tradicionales orientadas a la resolución de los conflictos en las comunidades indígenas}

Las prácticas indígenas orientadas a dar respuesta a la divergencia social no son homogéneas, sino que varían según la comunidad. Sin embargo, el rasgo característico de las formas de resolver los conflictos entre los comuneros es que se lleva a cabo frente a la autoridad tradicional. Para los pueblos ancestrales, la autoridad jurídica cumple también otras funciones como la política, religiosa y espiritual. ${ }^{37}$ Para la comunidad indígena de los pastos, ubicados en el municipio de Túquerres, al suroccidente colombiano, la calidad de la autoridad se deriva de la dignidad, la conciencia y la sabiduría de la persona, de que sepa dar lo mejor de sus capacidades a la comunidad y, a cambio, reciba aprecio, aceptación, reconocimiento y respeto

31 Actualidad Étnica, "Estrategias étnicas en la solución de conflictos", http://actualidadetnica.com/actualidad/ actualidad-col-01/politica/4181-estrategias-actnicas-en-la-soluciasn-de-conflictos.html (acceso octubre 3, 2018).

32 Sánchez Botero, "Principios básicos", 128.

33 María Socorro Granda Abella, "El 'patio prestado' frente a los principios de la justicia restaurativa", Criterio libre jurídico 8, núm. 2 (julio-diciembre 2011): 53, https://revistas.unilibre.edu.co/index.php/criteriojuridico/ article/view/751/584 (acceso octubre 3, 2018); comunero nasa, comunicación personal, octubre 3, 2018.

34 Sánchez Botero, Justicia, 156.

35 Gómez Valencia, Justicias indígenas, 357.

36 Gómez Valencia, Justicias indígenas, 201.

37 Pospíšil y Dubovický, Etnologie, 47. 
de la comunidad. ${ }^{38}$ Hay mucha variedad no solo respecto a las prácticas jurídicas, sino también a las autoridades tradicionales, proveniente de las costumbres de cada pueblo:

En la región amazónica las autoridades no son permanentes y su intervención depende del lugar que ocupan en las relaciones de parentesco. Al contrario, para la región andina es característico el sistema de Autoridades Permanentes con una centralización política a través de los cabildos. El sistema religioso propio de los grupos de la Sierra Nevada de Santa Marta y de la región amazónica y de algunos grupos de la región pacífica genera reglas de comportamiento fuertemente sacralizadas, y el sistema de Compensación Directa, propio de los indígenas Wayúu, se caracteriza por la presencia de palabreros amigables componedores, encargados de hacer las diligencias de transacción y negociación para compensar con bienes o servicios los daños u ofensas causadas entre clanes. ${ }^{39}$

En la comunidad nasa, el afectado se dirige al Cabildo a poner la queja; la oficina jurídica se encarga de la investigación y toma las decisiones. En los casos graves se reúne la Asamblea y elige la sanción. ${ }^{40}$ Las prácticas nasa orientadas a dar respuesta a la desarmonización buscan conocer las causas del conflicto para resolverlo adecuadamente y ayudar a las partes de la controversia y a la comunidad. Al impartir la justicia no se busca el castigo, sino la recuperación de la armonía comunal perdida, sin la presencia del espíritu de victoria o de venganza sobre el desarmonizado. ${ }^{41}$ En general, se pretende restaurar el estado previo a la desarmonización. ${ }^{42} \mathrm{~A}$ la hora de reaccionar ante el conflicto, la justicia nasa valora más las circunstancias del caso concreto y la relación de la persona con la comunidad que el mismo hecho o la falta cometida. ${ }^{43}$

El proceso ancestral es netamente oral: en busca de justicia, todos, sobre todo las partes del conflicto, tienen derecho a expresarse sobre los hechos. Estas suelen comparecer acompañadas por la familia y los amigos, quienes también pueden intervenir en la discusión de lo sucedido. Esta exposición pública es una

38 Consejo Yaichacuna del pueblo indígena del territorio de Túquerres, Sumas kawsay (El buen vivir) (Túquerres, 16 de noviembre de 2009), art. 19.

39 Gómez Valencia, Justicias indígenas, 169.

40 Comunero nasa, comunicación personal.

41 Gómez Valencia, Justicias indígenas, 374.

42 Comunero nasa, comunicación personal.

43 Cruz Rueda, "Principios generales", 40. 
manifestación de la solidaridad, de la participación colectiva en el conflicto y la regulación comunitaria de la sociedad. Se trata de un apoyo moral y afectivo que puede ser decisivo para adoptar la solución. ${ }^{44}$

La justicia en los pueblos indígenas se construye mediante la forma participativa, interpretativa y colectiva, en la cual los hechos, las circunstancias y las situaciones pueden ser narrados y comprendidos; con ello se conserva el sentido de sociedad y de pertenencia, lo que genera el sentimiento de participación en la vida común. Esta función narrativa o comunicativa de la justicia indígena implica la responsabilidad de los involucrados de mantener y permanecer en el grupo social. ${ }^{45}$

La reacción indígena frente al conflicto apunta a reconciliar, a llevar al transgresor a reconocer la responsabilidad por el error cometido, a pedir perdón a la víctima y a restaurar el estado inicial, con el fin de mantener la paz, la armonía y el equilibrio social.

La solución del conflicto consiste en la conciliación, la cual no es solo un medio para resolverlo, sino que es la finalidad misma. Es concebida como un ritual en el que se proyecta la cosmovisión indígena. Se enfoca sobre todo en la petición de perdón, lo que requiere el reconocimiento previo de haber cometido un error. La parte ofendida, al obtener del transgresor la promesa de buen comportamiento, deberá aceptar las disculpas y propiciar que se invierta la relación entre ellos. ${ }^{46} \mathrm{La}$ conciliación es la estrategia clave para solucionar las inconvenientes en la convivencia, cuyo fin es equilibrar las relaciones individuales y colectivas y armonizar sus vidas, al mantener las relaciones pacíficas. ${ }^{47}$

Al conocer los puntos clave de los métodos indígenas para dar la respuesta a la conducta socialmente reprochable ${ }^{48}$ y al señalar que el componente crucial de la justicia indígena es la reconciliación entre las partes del conflicto, el texto se

44 Adonon Viveros, "La conciliación", 98, 101.

45 Herinaldy Gómez Valencia, "Justicias orales indígenas y sus tensiones con la ley escrita" en Justicia y diversidad en América Latina: pueblos indígenas ante la globalización, ed. Victoria Chenaut et al. (Quito: Flacso, 2011), 411.

46 Adonon Viveros, "La conciliación", 102, 114.

47 Actualidad Étnica, "Estrategias étnicas".

48 Los cuales son los ritos y mitos, el reconocimiento de la comisión del error por el desviado, la curación del transgresor mediante consejos, el arreglo directo entre las partes en la conciliación, la institución de la reciprocidad y su correlato del don-perdón y el respeto por la naturaleza, sus representaciones y narrativas. Gómez Valencia, Justicias indígenas, 40. 
enfoca en los principios de la justicia restaurativa y sus puntos de encuentro con la justicia indígena.

\section{Justicia restaurativa}

La justicia restaurativa aparece en nuestro entorno cultural como un paradigma alternativo que critica las nociones tradicionales de delito y pena, ya que no está centrado en la punición, sino en la reparación y se fundamenta en tres ejes: la verdad, la justicia y la reparación. La justicia restaurativa supone reparar el daño, impedir que se repita, procurar la reeducación del criminal y el empoderamiento de las víctimas. ${ }^{49}$

Desde el punto de vista de la justicia restaurativa, la comisión de los hechos punibles causa daños a las personas y a las comunidades; por lo tanto, la justicia debe consistir, sobre todo, en la reparación de estos daños y el proceso de dar respuesta a la comisión del hecho punible debe contar con la participación activa de las partes del conflicto penal y de toda la comunidad. Se trata entonces de la justicia dialogada y participativa, de la gestión pacífica del conflicto por la vía de reconciliación entre la víctima y el ofensor, con atención a los intereses y a las necesidades de la víctima.

De acuerdo con las conclusiones del Primer congreso nacional de justicia restaurativa y oralidad:

[... la justicia penal restaurativa es una nueva escuela del derecho penal cuyo objeto de estudio son los protagonistas directos e indirectos del conflicto criminal. Aunque prioriza a las víctimas, proporciona un espacio al delincuente, cuya finalidad es atender sus necesidades y lograr su reinserción social. A los integrantes de la comunidad permite que participen en procesos en los que, además de aportar elementos para recuperar a la víctima y al delincuente, resulte factible comprender las causas del fenómeno criminal y superar la sensación de victimización social. ${ }^{50}$

49 Julio Andrés Sampedro Arrubla, "La justicia restaurativa: una nueva vía, desde las víctimas, en la solución al conflicto penal", Revista colombiana de derecho internacional 8, núm. 17 (2010): 97, 101, https://revistas. javeriana.edu.co/index.php/internationallaw/article/view/13821 (acceso octubre 3, 2018).

50 Jorge Pesqueira Leal, "Conclusiones del foro de análisis dialéctico sobre justicia penal restaurativa y salidas alternas al juicio oral. I Congreso nacional de justicia restaurativa y oralidad". http://justiciarestaurativamexico.blogspot.com/2010/12/conclusiones-i-congreso-nacional-de.html (acceso octubre 3, 2018). 
De la idea de la justicia restaurativa proceden prácticas cuyo objetivo es resolver conflictos por medio del diálogo y de la toma de decisiones de forma participativa. El proceso restaurativo brinda al infractor la posibilidad de reconocer la responsabilidad, mostrar arrepentimiento, pedir perdón a la víctima y ofrecerle reparación. Para la víctima, el proceso restaurativo es la oportunidad de expresarse y de ser escuchada. Perdonar al ofensor le ayuda a superar el trauma causado por la comisión del hecho punible y con la reparación — que va más allá de la mera reparación económica, pues abarca la reparación inmaterial o simbólica — se puede sentir satisfecha, lo que ofrece una respuesta efectiva a sus expectativas y necesidades. Pensar la justicia en una dimensión restaurativa implica reconocer a las víctimas como protagonistas del delito y significa dar la solución adecuada a la experiencia de la injusticia. ${ }^{51}$ Esta forma de justicia busca restaurar no solamente a las víctimas, sino también a los ofensores y a las comunidades, y estos objetivos adquieren prioridad sobre el castigo. ${ }^{52}$

La justicia restaurativa tiene raíces en ancestrales prácticas indígenas, las cuales hoy día se manifiestan en la sociedad occidental, sobre todo en los círculos sentenciadores y las conferencias de grupos de familia. En el círculo sentenciador participan la víctima, el ofensor y la comunidad afectada por el hecho ilícito; las conferencias familiares se usan para tratar con la delincuencia juvenil. Ambas prácticas restaurativas consisten en la comunicación en el círculo; la víctima puede expresarse frente al ofensor, quien puede explicar sus motivos y toda la comunidad puede intervenir y hacer sugerencias acerca de cómo reparar los daños causados por la conducta punible.

En conclusión, en el proceso restaurativo se puede solucionar el conflicto de forma oportuna, rápida y pacífica, superar el problema y aprender de él. Los elementos cruciales del proceso restaurativo son el diálogo, la posibilidad de expresar cara a cara los sentimientos y el daño causados por el delito y la asunción de la responsabilidad por los hechos cometidos.

Sampedro Arrubla, "La justicia", 95.

John Braithwaite, "Delito, vergüenza y reintegración", Delito y sociedad 2, núm. 32 (2011): 15, https:// bibliotecavirtual.unl.edu.ar/publicaciones/index.php/DelitoYSociedad/article/view/5646/8394 (acceso octubre 3, 2018). 


\section{Comparación de la justicia restaurativa y la indígena en materia penal}

La justicia indígena y la restaurativa se soportan en el diálogo. El hecho se construye mediante la palabra —el habla común—, interpelándolo, debatiéndolo y explicándolo, lo que genera el sentimiento de participación en la vida social y de pertenencia a la comunidad. ${ }^{53}$

Narrar lo que sucedió, sin negar los hechos, lleva al transgresor a reconocer la responsabilidad por lo que ha cometido, lo que es la conditio sine qua non para poder pedir el perdón a la víctima. La cosmovisión indígena interpreta que negarse a reconocer la responsabilidad es negarse a solicitar el perdón y a ser perdonado; la negativa es considerada como una ofensa grave contra la comunidad y la tradición, como un acto de sustracción y ofensa a la justicia y como la razón por la cual es castigada. Por lo tanto, en el proceso indígena de hacer justicia se requiere —en la terminología occidental-la confesión del culpable, denominada por los nasa como "remedio para hacer responder" (kpasu'jua' yu'çe)..$^{54}$

Admitir haber cometido la ofensa que originó el conflicto y tomar la iniciativa de buscar una solución es el paso necesario para la solicitud del perdón. Esto lleva a la parte ofendida a discutir sobre las posibles vías de solución y aceptar alguna de ellas; en tal situación; la persona afectada no tiene por qué rechazar una propuesta de arreglo del conflicto. ${ }^{55}$ El verdadero perdón supone que la víctima conozca al transgresor y este, a su vez, se encuentre en disposición de pedirlo, ya que para que el perdón pueda ser concedido, es necesario que sea solicitado. ${ }^{56}$

La justicia indígena no busca restituir al transgresor al orden cultural mediante el castigo, sino por medio del perdón, ${ }^{57}$ en este aspecto se relaciona con la justicia restaurativa.

Otro punto de encuentro entre ambas consiste en la importancia de que el transgresor comprenda las consecuencias de su conducta. En la justicia indígena, este fin se logra mediante la figura del consejo y la práctica de aconsejar. Conforme a la

Gómez Valencia, "Justicias orales", 411.

Gómez Valencia, Justicias indígenas, 118.

Adonon Viveros, "La conciliación", 103.

Sampedro Arrubla, "La justicia", 100.

Gómez Valencia, "Autoridad", 692. 
cosmovisión wayuu, puede aconsejar solo quien ha cometido errores, porque tiene la experiencia vivida y venida del error, ya que solo por esta puede comprender al otro y aconsejarle. ${ }^{58}$ Según los nasa, aconsejar a la persona tiene el propósito de regresarla a la sociedad con igual valor y respeto que los demás integrantes de la comunidad y que la comunidad quede satisfecha y olvide que la persona estuvo enferma; entonces, si la persona ha cometido una desarmonización, hay que reintegrarla a la comunidad mediante la ayuda de consejeros, otorgada en el encuentro conciliatorio.

El proceso de construir justicia según los nasa se funda en la relación de tres hechos o palabras: yuwe, cu'le y yu'çe; yuwe es la causa que permitió al individuo dañarse, enfermarse o torcerse; cu'le es el camino para enderezar al individuo, siempre en función de mejorar no sólo en forma personal sino en forma colectiva; y yu'çe es el recurso o remedio que permite alcanzar la solución mediante el consejo que permite al enfermo aprender y aceptar el remedio con el objetivo de regresar a la sociedad; igualmente, es la capacidad de los consejeros para que la solución realizada permita que la comunidad quede satisfecha y olvide que la persona estuvo torcida o enferma. ${ }^{59}$

La corrección de la persona mediante los consejos representa para las sociedades prehispánicas una forma de control social. ${ }^{60}$ En las comunidades andinas, el control social apunta a provocar en la persona desarmonizada el sentimiento de vergüenza que la lleva a reconocer la gravedad del hecho, a pedir perdón, a aceptar el consejo y a cumplir las sanciones y, con ello, reencontrarse con la comunidad. ${ }^{61}$ Según los nasa, la vergüenza se genera mediante el escarnio público, con hacer sentir al desarmonizado la presión moral de la comunidad. ${ }^{62}$

La pretensión de que el transgresor sufra y sienta vergüenza es otro punto de encuentro entre la justicia indígena y la restaurativa, ya que la percepción indígena ideológicamente corresponde con la teoría de la vergüenza reintegrativa de John Braithwaite. Con la vergüenza reintegrativa se pretende rechazar el acto cometido

\footnotetext{
Gómez Valencia, Justicias indígenas, 193.

Gómez Valencia, Justicias indígenas, 373.

Sánchez Botero, Justicia, 157.

Gómez Valencia, "Autoridad", 693.

Comunero nasa, comunicación personal.
} 
y no a la persona desviada, a quien hay que respetar y reaceptar. ${ }^{63}$ Provocar vergüenza en el infractor no se trata de humillarlo, degradarlo ni estigmatizarlo, ya que la estigmatización implica el no-perdón; si el ofensor es tratado como una mala persona y es rechazado por la sociedad, su reacción será rechazar a quienes lo rechazan ${ }^{64}$ y estas circunstancias impedirán su reaceptación por la sociedad y su reintegración a esta. Además, la teoría de la vergüenza reintegrativa parte de la premisa de que cometer un error no quiere decir que el transgresor sea mala persona. La comisión del error significa la oportunidad para que la persona aprenda, pues este tipo de vergüenza la lleva a reflexionar sobre el hecho y a ser consciente de lo que ha cometido y, si se combina con el arrepentimiento, se alcanza el olvido, el perdón y, como fin, la paz social.

La teoría de la vergüenza reintegrativa parte del modelo familiar o comunitario de resolución de conflictos, basado en la idea de que al transgresor no le importa la opinión que tiene sobre él una persona desconocida o ajena que puede ser un juez o cualquier tercera persona, pero sí le importa cómo lo percibe su entorno social. Cuanto más fuerte es la comunidad, más eficaz es la teoría de la vergüenza reintegrativa, porque el alto grado de control social tiene un gran alcance preventivo, proveniente no del miedo del transgresor a ser castigado, sino a ser avergonzado de nuevo. ${ }^{65}$

El enfoque al problema — sin rechazar el transgresor- y la reintegración de la persona que ha cometido un hecho dañino al grupo social son puntos de encuentro entre la justicia indígena y la restaurativa. En los pueblos ancestrales, el primer paso para el regreso a la comunidad consiste en la limpieza espiritual del enfermo. ${ }^{66}$

La purificación del desarmonizado es también el principio central del sistema indígena de castigos, que es el área con la mayor influencia de la cosmovisión indígena, con la función ritual y simbólica propia, sobre todo para los castigos corporales. Respecto a las sanciones resulta imprescindible conocer muy bien la cosmovisión indígena y entender sus valores, descartando el punto de vista occidental. Los castigos físicos no son sanciones en sentido estricto, ya que se usan también para que el transgresor reconozca su hecho dañino frente la autoridad, lo que resulta necesario para que la

\footnotetext{
63 Miguel Langón Cuñarro, "La teoría de la vergüenza reintegrativa de John Braithwaite", Revista de la Facultad de Derecho, núm. 18 (diciembre 2000):64, https://revista.fder.edu.uy/index.php/rfd/article/view/267 (acceso octubre 3, 2018).

64 Braithwaite, "Delito", 7, 11.

65 Langón Cuñarro, "La teoría", 65.

66 Actualidad Étnica, "Estrategias étnicas".
} 
comunidad lo acepte de nuevo y pueda reincorporarse. Por ejemplo, las prácticas consistentes en el baño en agua fría y el ortigamiento, usadas por las comunidades andinas, tienen como objetivo curar al enfermo, limpiar su cuerpo de los malos espíritus, restablecer el equilibrio y regresar a la paz. ${ }^{67}$ Asimismo, la finalidad de la sanción del fuete no es causar sufrimiento al individuo, sino purificarlo con el rayo, por lo cual se trata de una figura simbólica que representa un ritual de la comunidad para sancionarlo, transformarlo, recuperar su lugar en la comunidad y devolverle la armonía. ${ }^{68} \mathrm{Al}$ respecto, la Corte Constitucional colombiana declaró la constitucionalidad de la sanción del fuete. ${ }^{69}$ En la Sentencia de T-349 de 1996 reconoció la constitucionalidad del cepo, otro castigo corporal frecuentemente usado por algunas comunidades indígenas. ${ }^{70}$ En ambas Sentencias la Corte afirmó que estas sanciones no constituían un trato cruel e inhumano.

A pesar de que en el sistema indígena de castigos están presentes la espiritualidad y la ritualidad, este procede, igual que en el paradigma restaurativo en la justicia penal occidental, del principio de rehabilitación o reinserción social del enfermo/ ofensor. Su objetivo es que el transgresor quede en paz con él mismo y con su sociedad nativa. Por ejemplo, cada golpe del fuete viene acompañado con un consejo orientado a mejorar a la persona que se ha desarmonizado. ${ }^{71}$ Para el sistema indígena sancionador, la sanción apunta a ser un verdadero correctivo, por lo cual no debe distanciarse de las causas de la conducta desviada del orden social, sino dar la respuesta adecuada a la conducta en cada caso concreto; "y más que castigar debería buscar desarrollar formas de integración y solidaridad social para enfrentar colectivamente todo lo que atente contra la tradición y la convivencia social". ${ }^{72}$

Al sistema de castigos se suma el principio central de la convivencia en los pueblos de origen prehispánico — la reciprocidad—, el cual se observa, sobre todo en la sanción con trabajos comunitarios aplicada en todo tipo de sistemas jurídicos aborígenes. En la comunidad nasa se cumple en los centros de armonización, donde, aparte de los trabajos, se realizan rituales de armonización con las personas que han cometido los hechos dañinos. Al ejecutar trabajos en favor de la comunidad se gana de nuevo su respeto; es la manera de compensar los daños causados al grupo

\footnotetext{
67 Emiliano Borja Jiménez, "Sobre los ordenamientos sancionadores originarios de Latinoamérica" en Pueblos indígenas y derechos humanos, ed. Mikel Berraondo López (Bilbao: Universidad de Deusto, 2006), 130.

68 Corte Constitucional, Sentencia T-523 del 15 de octubre de 1997, M. P. Carlos Gaviria Díaz.

69 Corte Constitucional, Sentencia T-523 del 15 de octubre de 1997.

70 Corte Constitucional, Sentencia T-349 del 8 de agosto de 1996, M. P. Carlos Gaviria Díaz.

71 Borja Jiménez, "Derecho indígena", 18, 20

72 Gómez Valencia, Justicias indígenas, 197.
} 
social, que lleva a la persona comprender la importancia de velar por los intereses comunales. Además, mientras cumple la sanción, la persona no deja de participar en las actividades colectivas; al contrario, se está reintegrando al grupo social y fortaleciendo la solidaridad dentro de la comunidad. En los daños de naturaleza patrimonial cabe la reparación de la víctima como una forma de restauración del estado previo a la desarmonización. ${ }^{73}$

La sanción no apunta a expresar solamente el castigo, sino — sobre todo— restaurar la armonía, el equilibrio de la vida social del grupo étnico y la paz rota. ${ }^{74}$ Además de reingresar al desarmonizado a la comunidad, se busca también reparar los daños causados a toda la comunidad porque, según la cosmovisión indígena, es una exigencia de convivencia. ${ }^{75}$

La importancia de la reparación y el propósito resocializador de la pena coinciden con la teoría de Claus Roxin sobre la reparación como la tercera vía de resolución de conflictos penales, que sostiene que si la reparación es la suficiente consecuencia jurídica del conflicto penal, ya no se necesita imponer la pena y, si la reparación no basta por sí sola, debería por lo menos moderar la pena. ${ }^{76}$ Asimismo, la reparación no se considera como una cuestión meramente jurídico-civil, sino que cumple con los fines de la pena y sugiere que, más que enfocarse en castigar al infractor, la pena debería intentar satisfacer a la víctima atendiendo sus necesidades; tiene alcance resocializador y preventivo, ya que obliga al infractor a enfrentarse a las consecuencias de su conducta y a aprender de ellas al conocer los intereses legítimos de la víctima. ${ }^{77}$

La idea de la reparación está presente tanto en la justicia indígena como en la restaurativa, con la diferencia de que en la filosofía ancestral se trata de la reparación de toda la comunidad, mientras que la justicia restaurativa busca la reparación del daño causado a la víctima concreta. Por otra parte, en ambas está presente la dimensión simbólica de la reparación, es decir, el objetivo de la reparación no es solamente la indemnización material o financiera, sino la plena satisfacción de la víctima (sea la persona afectada por el hecho punible o toda la comunidad).

Comunero nasa, comunicación personal.

74 Borja Jiménez, "Sobre los ordenamientos", 125.

75 Gómez Valencia, Justicias indígenas, 201.

76 La teoría de Claus Roxin ofrece la alternativa tanto a la justicia retributiva, que destaca la imposición de la pena, como a la justicia rehabilitadora, basada en la idea del tratamiento.

77 Sampedro Arrubla, "La justicia", 105. 
También comparten la idea de la transformación de las relaciones sociales tras la reparación y buscan la restitución del estado previo al conflicto.

El punto de partida de la reparación o restauración del Estado antes del conflicto es el reconocimiento de la responsabilidad por el ofensor ante la víctima, la reparación, por lo tanto, manifiesta la activa actitud del transgresor frente a las consecuencias de su conducta lo que tiene un gran alcance preventivo. La función preventiva también cumple el ejercicio público del castigo, como se observa en el pueblo paez, ya que así disuade a los demás miembros de la comunidad de cometer faltas y al propio transgresor, de reincidir. ${ }^{78}$ La reparación o restauración, así como la prevención general e individual, son otros puntos de encuentro entre la justicia indígena y la restaurativa.

En conclusión, la justicia indígena y la restaurativa provienen de distintos sistemas de valores: la primera refleja la cosmovisión propia de los pueblos ancestrales y la segunda es un concepto creado por la cultura jurídica occidental. Sin embargo, tienen puntos de encuentro: i) énfasis en el carácter interpersonal del conflicto; ii) el diálogo y la reconciliación como reacción a la controversia; iii) la forma pacífica, colectiva y consensual de responder al conflicto; iv) reconocimiento de responsabilidad, aprendizaje de los errores cometidos y petición de perdón por el transgresor; v) concesión del perdón por la parte de la víctima; vi) reintegración del transgresor a la sociedad; vii) participación de la comunidad en la respuesta a la comisión del hecho divergente; viii) restauración de las relaciones interpersonales y de la paz social y jurídica, y ix) el alcance preventivo de los métodos de resolución del conflicto.

\section{Conclusión}

Colombia, como Estado étnica y culturalmente diverso, cuenta con la existencia tanto de la sociedad hegemónica como también de los pueblos ancestrales, los cuales tienen su propia forma de desarrollar la vida en comunidad bajo los principios y valores transmitidos oralmente por varias décadas, paralela a la organización administrativa, política y jurídica del Estado. ${ }^{79}$ Las costumbres y tradiciones indígenas, incluida la forma de administración de justicia, proceden de su propia cosmovisión y tienen

\footnotetext{
78 ánchez Botero, "Principios básicos", 129

79 Rodríguez, Acceso a la justicia, 14.
} 
carácter simbólico. La simbología se refleja, sobre todo, en los castigos con los que se busca la limpieza espiritual y la purificación del desarmonizado.

Aunque las prácticas jurídicas varían de acuerdo con la comunidad, las principales características de la justicia indígena en materia penal son la publicidad y oralidad de la reacción ante la conducta dañina, en la cual se discuten y se explican los hechos bajo la conducción de la autoridad y con la intervención tanto de las partes del conflicto como de otros miembros de la comunidad; se trata de una justicia consensual y colectiva con énfasis en su función narrativa y comunicativa. Construir la justicia tiene como objetivo la reconciliación de las partes; la reparación del daño causado; la restitución del estado previo a la desarmonía; el sentimiento de vergüenza del transgresor y su petición de perdón y el rechazo moral de la comunidad, así como su reintegración social; el mantenimiento del equilibrio, de la armonía y de la paz en la comunidad.

La justicia indígena y la restaurativa tienen varios puntos de encuentro y, a pesar de que provienen de ideologías distintas, la primera puede servir como una rica fuente de inspiración para el desarrollo de alternativas a la justicia penal ordinaria. Incluso la ONU relaciona la forma de solucionar conflictos de los grupos indígenas con la justicia restaurativa y la misma referencia se hizo también en el primer congreso nacional mexicano de justicia restaurativa y oralidad, celebrado en el año 2010 en Acapulco.

Hoy en día, la tendencia mundial es la búsqueda de alternativas al derecho penal, incluidas las ideas y los mecanismos de la justicia restaurativa, la cual constituye una visión diferente del sistema ordinario. Sin embargo, no pretende quitar al Estado el derecho de perseguir el delito ${ }^{80}$ ni reemplazar la justicia penal, sino complementarla y enriquecerla con los mecanismos que promuevan soluciones adecuadas a las necesidades de las partes involucradas. A diferencia del proceso penal estatal, que se enfoca en la persecución del delincuente y olvida a la víctima, el paradigma restaurativo destaca la importancia de las víctimas y otorgarles el protagonismo en la reacción al conflicto penal, para que sean escuchadas y atendidas. Al ofensor le ofrece la posibilidad de reparar las consecuencias de su conducta ilícita, lo que tiene también connotaciones preventivas.

80 Sampedro Arrubla, "La justicia", 91. 
Con el ejemplo indígena se pretende apoyar la implementación de las ideas de la justicia restaurativa y sus mecanismos en el derecho penal, para ofrecer una respuesta adecuada y eficaz a la criminalidad. Se propone que la justicia ordinaria sea más informal y más comunicativa, sin rechazar a priori el encuentro entre las partes del conflicto, sino con la creación del espacio de mutuo respeto donde se escuche, se dialogue, se pueda expresar sobre los hechos, se pida perdón y se perdone. Se desea que el proceso penal se enfoque en la verdadera solución del conflicto, que intente conocer las causas de la comisión del hecho punible y la motivación del infractor y que busque, donde sea apropiado, el consenso antes que la persecución y punición del delincuente. También se quiere fortalecer el aspecto comunitario en la sociedad occidental, con lo que se aumentaría el control social y así se reduciría la criminalidad.

La justicia indígena nos muestra que la justicia penal puede tener un contenido reconciliador, resocializador, reparador, restaurativo y preventivo, antes que represivo y punitivo.

\section{Referencias}

Actualidad Étnica. "Estrategias étnicas en la solución de conflictos". http://actualidadetnica. com/actualidad/actualidad-col-01/politica/4181-estrategias-actnicas-en-la-soluciasnde-conflictos.html (acceso octubre 3, 2018).

Adonon Viveros, Akuavi. "La conciliación: ¿Un medio o un fin en la solución de conflictos?" en Hacia sistemas jurídicos plurales, reflexiones y experiencias de coordinación entre el derecho estatal y el derecho indigena, editado por Rudolf Huber, Juan Carlos Martínez, Cécile Lachenal y Rosembert Ariza, 87-118. Bogotá: Anthropos, 2008.

Ariza Santamaría, Rosembert. "Estado del relacionamiento en Colombia" en Estado de la relación entre justicia indígena y justicia estatal en los países andinos. Estudio de casos en Colombia, Perú, Ecuador y Bolivia, editado por Comisión Andina de Juristas, 15-38. Lima: Comisión Andina de Juristas, 2009.

Benavides Ascuntar, Jorge Enrique. "La jurisdicción indígena en el sistema penal acusatorio". Entramado 7, núm. 2 (julio-diciembre 2011): 98-114, http://www.scielo.org.co/pdf/ entra/v7n2/v7n2a07.pdf (acceso octubre 3, 2018).

Borja Jiménez, Emiliano. "Derecho indígena, sistema penal y derechos humanos". Nuevo foro penal 5, núm. 73 (2009): 11-46, https://dialnet.unirioja.es/descarga/articulo/3822976. pdf (acceso octubre 3, 2018). 
Borja Jiménez, Emiliano. "Sobre los ordenamientos sancionadores originarios de Latinoamérica" en Pueblos indígenas y derechos humanos, editado por Mikel Berraondo López, 663-684. Bilbao: Universidad de Deusto, 2006.

Braithwaite, John. "Delito, vergüenza y reintegración". Delito y sociedad 2, núm. 32 (2011): 7-18, https://bibliotecavirtual.unl.edu.ar/publicaciones/index.php/DelitoYSociedad/ article/view/5646/8394 (acceso octubre 3, 2018).

Cárdenas Hernández, Carlos Alfonso y Pedro Alfonso Sánchez Cubides. "El pluralismo jurídico en la jurisdicción indígena y el buen vivir en Colombia". Criterio jurídico garantista 9, núm. 15 (julio-diciembre, 2016): 114-125, http://revistas.fuac.edu.co/ index.php/criteriojuridicogarantista/article/view/646/599 (acceso octubre 3, 2018).

Consejo Yaichacuna del pueblo indígena del territorio de Túquerres. Sumas kawsay (El buen vivir). Túquerres, 16 de noviembre de 2009.

Corte Constitucional. Sentencia T-349 del 8 de agosto de 1996. M. P. Carlos Gaviria Díaz.

Corte Constitucional. Sentencia T-523 del 15 de octubre de 1997. M. P. Carlos Gaviria Díaz.

Cruz Rueda, Elisa. "Principios generales del derecho indígena" en Hacia sistemas jurídicos plurales, reflexiones y experiencias de coordinación entre el derecho estatal y el derecho indigena, editado por Rudolf Huber, Juan Carlos Martínez, Cécile Lachenal y Rosembert Ariza, 29-50. Bogotá: Anthropos, 2008.

Gómez Valencia, Herinaldy. "Autoridad y control social en pueblos indígenas andinos de Colombia”. Ra Ximhai 2, núm. 3 (septiembre-diciembre 2006): 683-716, https:// dialnet.unirioja.es/descarga/articulo/2213976.pdf (acceso octubre 3, 2018).

Gómez Valencia, Herinaldy. "Justicias orales indígenas y sus tensiones con la ley escrita" en Justicia y diversidad en América Latina: pueblos indígenas ante la globalización, editado por Victoria Chenaut, Magdalena Gómez, Héctor Ortiz y María Teresa Sierra, 407-426. Quito: Flacso, 2011.

Gómez Valencia, Herinaldy. Justicias indígenas de Colombia: reflexiones para un debate cultural, jurídico y político: pueblos Kogui, Arhuaco, Wiwa, Kankuamo, Nasa, Misak, Yanacona y Camëntŝá. Bogotá: Consejo Superior de la Judicatura, 2015.

Granda Abella, María Socorro. "El 'patio prestado' frente a los principios de la justicia restaurativa”. Criterio libre jurídico 8, núm. 2 (julio-diciembre 2011): 47-62, https:// revistas.unilibre.edu.co/index.php/criteriojuridico/article/view/751/584 (acceso octubre 3, 2018).

Griffiths, John. "¿Qué es pluralismo jurídico?" en Pluralismo jurídico, editado por Sally Engle Merry, John Griffiths y Brian Tamanaha, 142-220. Bogotá: Universidad de los Andes, 2007.

Gutiérrez, Marcela. "Pluralismo jurídico y cultural en Colombia". Derecho del Estado, núm. 26 (enero-junio 2011): 85-105, http://www.scielo.org.co/pdf/rdes/n26/n26a04.pdf (acceso octubre 3, 2018). 
Langón Cuñarro, Miguel. "La teoría de la vergüenza reintegrativa de John Braithwaite". Revista de la Facultad de Derecho, núm. 18 (diciembre 2000): 63-68, https://revista. fder.edu.uy/index.php/rfd/article/view/267 (acceso octubre 3, 2018).

Llano, Jairo Vladimir. "Relaciones entre la sociología y la antropología jurídica en Latinoamérica”. Iusta 2, núm. 33 (2010): 103-115, https://revistas.usantotomas.edu. co/index.php/iusta/article/view/3098 (acceso octubre 3, 2018).

Llano, Jairo Vladimir. Teoría del Estado y del derecho: pluralismo jurídico. Bogotá: Ibáñez, 2017. Organización Internacional del Trabajo [OIT]. Convenio núm. 169 de la OIT sobre pueblos indígenas y tribales en países independientes. Ginebra, 7 de junio de 1989.

Pesqueira Leal, Jorge. "Conclusiones del foro de análisis dialéctico sobre justicia penal restaurativa y salidas alternas al juicio oral. I Congreso nacional de justicia restaurativa y oralidad". http://justiciarestaurativamexico.blogspot.com/2010/12/conclusiones-icongreso-nacional-de.html (acceso octubre 3, 2018).

Pospíšil, Leopold Jaroslav e Ivan Dubovický. Etnologie práva: teze ke studiu práva z mezikulturní perspektivy. Praga: Setout, 1997.

Rodríguez, Javier. Acceso a la justicia de los pueblos indígenas: guía para la atención especializada por parte de las oficinas del Ombudsman. San José: Instituto Interamericano de Derechos Humanos, 2006.

Sampedro Arrubla, Julio Andrés. "La justicia restaurativa: una nueva vía, desde las víctimas, en la solución al conflicto penal". Revista colombiana de derecho internacional 8, núm. 17 (2010): 87-124, https://revistas.javeriana.edu.co/index.php/internationallaw/ article/view/13821 (acceso octubre 3, 2018).

Sánchez Botero, Esther. "Principios básicos y formas de funcionamiento de la justicia que se imparte entre los paeces y los wayuu como forma cultural adecuada, legítima y viable para resolver conflictos y coaccionar a sus sociedades particulares" en Hacia sistemas jurídicos plurales, reflexiones y experiencias de coordinación entre el derecho estatal y el derecho indígena, editado por Rudolf Huber, Juan Carlos Martínez, Cécile Lachenal y Rosembert Ariza, 119-150. Bogotá: Anthropos, 2008.

Sánchez Botero, Esther. "Reflexiones antropológicas en torno a la justicia y la jurisdicción especial indígena en una Nación multicultural y multiétnica" en Las sociedades interculturales: un desafío para el siglo XXI, coordinado por Fernando García, 57-84. Quito: Flacso, 2000.

Sánchez Botero, Esther. Justicia y pueblos indígenas de Colombia: la tutela como medio para la construcción de entendimiento intercultural. Bogotá: Universidad Nacional de Colombia, 1998.

Wolkmer, Antonio Carlos. Pluralismo jurídico: nuevo marco emancipatorio en América Latina. Buenos Aires: Cenejus, 2003. 